\title{
Factors that determine job performance
}

\author{
Georgeta Amalasunta Iacob, „Al. I. Cuza” University of Iasi, Romania
}

\begin{abstract}
In today's context is seeking various solutions to determine that employees receive performance at work. Most of the hand is to motivate people in terms of promoting strategic management objectives. Only that the motivation and objectives involved a number of factors that can influence the performance of employees much more than motivation itself. The case study presented in this study will prove this.
\end{abstract}

\section{Keywords}

Job performance, types of performance, Big Five, to influence

\section{JEL Codes: M 12}

\section{Introduction}

The aim of the research is human resource management namely the factors who can influence or determinate the performance of the employee at the work place. I'm speaking about the "job performance" concept defined in quality and quantity terms of the employers activity, personality factors, skills and abilities necessary which can predict the employees performance or performance evaluation.

The problem with which I started is that one that long time of my short career in human resource I had to face with different materials used for recruitment and selection process in performance for performances evaluation or periodic evaluations who sometimes were incomplete or had to be adapted, but mostly I find difficulties in the way that some selected persons was manifesting performance in terms of technical or operational skills and not in terms of temperament or attitude. They had also a very good capacity for self-monitoring in the way that it influenced in positive mode the evaluation results. Also, the employers many times were unsatisfied by the fact that the professiograms, the questionnaires used weren't satisfied specially when it was talking about employments in keys positions where they wanted to have ideal employees. As well the researches made in this area were axed on socio-professional categories (students, manager, IT, employees in industrial, medical or military area) but less on professional levels, number of years experience or longitudinal studies for enhance this type of professiogram or questionnaires to assess performance, in the way to obtain a standard for a certain professional category and in the comparison between the candidate and the standard one to make an assessment of candidate/employee.

\section{The main ideas about the theme of research}

Interactionist paradigm in its attempt to conceptualize the work, in terms of psychological theory considers that the operation is the result of ongoing interactions between personal factors, situational, behavioral (Bandura, 1977, Schneider 1983). According to this interpretation, we can say that (a) the individual shapes the environment to find ways to facilitate certain results, (b) the same environment gives rise to different reactions to 
different individuals, (c) the same environment has different impact on the same individual, depending the mood of the individual. In other words, personality traits they possess individuals can be triggered by various situational factors, because the latter can diminish or decrease the expression of personality in work behavior and, therefore, is necessary to explain how personality affects performance work. (Tett \& Burnett, 2003). In accord with this perspective, we believe that people who undertake a proactive personality in their environment to facilitate high levels of performance and is a positive predictor for individual performance and behavioral organizational citizenship. [11, pp. 165-212; 14, pp. 258-266]

Locke's and Latham (1990) theory of setting targets which suggests that human exposure is a cause of objective behavioral manifestations and individual performance can be maximized when (a) they establish specific and difficult targets to have high valences and (b) they understand that behavior consistent with the objectives and they feel able to do so. Characteristics of targets are used to predict employment outcomes, but no attention is paid to the fact that different content of regulatory objectives and modes of conduct may lead to performance objectives of a qualitatively different (Sheldon \& Elliot, 1999, Sheldon, Ryan , So, \& Kasser, 2004).

Regulation theory of action arose to examine motivation in the workforce, but other things including performance. Cyber field is strongly influenced by where he used the concept of goals and highlights mechanisms by which individuals are focused on specific target of action (Fresia \& Sabin, 1991, Hacker, 1994). The theory includes the concept of discretion associated with the concept of self-determination theory. Fresia (1989) believes that self control combined with optimal complexity of the task without undue complications, lead to optimal performance and well done feeling.

Job characteristics theory developed by Hackman and Oldham (1980) argues that the most effective means to motivate individuals is job design. The authors propose ways of improving performance through job design to (1) to provide variety, involving the completion of all tasks and have impact on the lives of all, (2) offer considerable freedom and discretion to employees, (3) to provide full performance feedback. The authors explain that individual differences should be moderate so that job characteristics have a positive impact on performance at work.

Self-determination theory distinguishes between two concepts: autonomous motivation and controlled motivation, developing in particular the first concept that involves action in the sense of initiative and experience of choosing alternative. Autonomy in this context, allows the highest degree of reflection, because they believe that purchasing task is interesting and not because it "must" to do that action. Intrinsic motivation is just one example of autonomy. It is opposed or only partially supports the concepts of other theories, restricting individual autonomy to act in their desire to be free to choose activities of the closest individual, not to be influenced by setting objectives, defining characteristics of the job, because it can not have alternative perspectives and thus one becomes controlled, limited and no longer get the best performance. This explains why external rewards do not always produce the desired performance (Eden, 1975, Deckop and Cirka, 2000). Theory also found individual differences of people on their guidelines in the process of initiating and regulating their behavior. Referring to the guidelines of causality (So \& Ryan, 1985b), they indicate the degree to which people are self-directed (reflecting the general tendency to experience social contexts as autonomy supportive and be self-determined), control-oriented (reflecting general tendency to experience social contexts controlling and controlled) and impersonally directed (reflecting the general trend to be unmotivated).

Research has shown that understanding the relationship required to differentiate performance results in terms of "if" task is relatively simple, involving applications tiring on the algorithm, or is more difficult to initiate tasks, flexible, creative, heuristic-do (McGraw, 1978). Laboratory experiments have shown that autonomy is associated with a more efficient performance in terms of complex tasks, while there is no difference in short-term advantage to control performance when well establish tasks are initiated (Amabile, 1982; Grolnick \& 
Ryan, 1987, McGraw \& McCullers, 1979). Koestner and Losier's research (2002) has made another important difference, namely that intrinsic motivation leads to a better performance on tasks that are interesting, but not autonomous and extrinsic motivation leads to a better performance for tasks which are not very interesting, but are important and require discipline and determination. All these studies suggest that self-motivation, consisting of a mix between intrinsic motivation and internalized extrinsic motivation is higher in situations that include both complex tasks that incites interest and less complex tasks that require discipline. They are paradigms that theoretical research validates them as generally representative for performance at work, among other perspectives and theories, but my research I believe that the above will help me to get my focus and not deviate from the objective, to not ignore that the perspective can change evolving process of deforestation and research. [8, pp.333-350].

\section{The Performance: dimensions and his factors}

Many studies have examined the multidimensional and complex construct of "job performance". Among the most accepted theories are working performance JP Campbell (1990) describes the work as a performance variable individually. Performance is what one person can make a distinguished performance and management. Campbell, McHenry, and Wise (1990) have identified 8 major dimensions of performance: (1) specific tasks the job skills, (2) tasks nonspecifice job skills, (3) tasks of writing and oral communication, (4) demonstrating effort; (5) maintaining personal discipline, (6) facilitation of pair and team performance, (7) supervision and (8) management and administration. In the literature, individual performance dimensions include production facilities, quality of work, ownership, supervision and leadership skills, performance, lost time, turnover, during training, promotion and satisfaction.

Hunter \& Hunter (1984) describes the characteristics that may predict future job performance. List includes past performance relative to the position currently held knowledge about the post, psychomotor skills, cognitive, social and attitude on post such as the need for learning, enthusiasm, and control stress. Viswesvaran, Ones, and Schmidt (1996) identified 10 dimensions of work performance: (1) overall performance, (2) work performance or productivity, (3) quality (4) leadership, (5) communication skills (6 ) administrative powers (7) effort (8) interpersonal competence, (9) knowledge of the post (10) compliant or accepting authority. Witt, Burke, Barrick and Mount (2002) identified 11 dimensions: quality of work, quantity of work, initiative, communication with customers, planning, commitment to organization, job knowledge, allocation, interpersonal orientation, self-determination and funds management. Literature tries to include, besides those mentioned above, organizational citizenship behavior refers to behaviors beyond the skills required by tasks (Organ, 1997). [7, pp.593-597, 9, pp 38-61].

Others distinguished between task performance and contextual performance. Performance that takes the load is defined by those comportamentecare are formally recognized as part of the job and contribute directly or indirectly organizations technical basis. Contextual performance is defined by those behaviors that do not directly provide technical support activities, but rather the organizational environment, social and psychological as technical work is conducted (Motowidlo \& Van Scotter, 1994, Borman \& Motowidlo, 1997). In the literature studying the quality of life at work, the two forms of performance overlap.[2, pp.31-33]

Two types of performance tasks are supported by Conway (1999): (1) technicaladministrative task performance, (2) performance tasks of leadership.

Technical-administrative task performance includes all non-leadership tasks such as paperwork, organization, planning, quality, quality performance, financial decisions. However, performance leadership tasks require human relations and people management and motivation, supervision and evaluation of subordinates. Performance tasks of leadership is distinguished from contextual performance is that the first one is specific oriented to the 


\section{Studies and Scientific Researches - Economic Edition, no. 15, 2010}

objectives and focuses primarily on the guidance and motivation, while contextual performance highlights the moral and promoting the participation of employees in organization's concern (Conway, 1999). [4,798-803]

Employees normally engage in two types of performance: in-role performance and extrarole. The first is defined as those results and conduct the required official, sour serve directly targets organization (Motowidlo \& Van Scotter, 1994). In addition, employees have and extra-role activities (Morrison, 1994) which is defined by those discretionary behaviors that believes and promotes the effective functioning of the organization, without directly affecting productivity targeted employees (Podsakoff \& MacKenzie, 1994). [1,pp. 78-95]

The link between job satisfaction and work performance is an investigation of "Saint Gral" in terms of organizational behavior (Weiss \& Cropanzano, 1996), because the link between them, according to research, is positive but weak material. Often these two concepts overlap, the theory of the employee happy, but is identical in that employee satisfaction causes job performance, but if the employee is satisfied it will motivate them to achieve performance. That you seek to avoid objective and well reasoned as possible, to bring in my research concerns the satisfaction at work. [5, pp 755-760].

But Rose (2003; 2000b) also suggests that the significance of the workplace sociopsychological environment is overstated by many of the management theorists. The author conceptualises job satisfaction around the extrinsic aspects of employment with underpinning notion of economic rationality. Significant factors in that respect are: terms and conditions of the employment contract; hours of work; money rewards; the work situation and orientation and career aims of the employees (2003:509). Consequently, employees viewpoint should be considered with emphasis on these factors: they represent the core of job satisfaction and are therefore conditioning the existence of good jobs.

Most of studies provide so little details of the variables that it is difficult to gauge the extent to which practices really do match (Hutchinson et al. 2003).

Performance measures also vary. In the majority of the empirical work on the link between HRM and performance, performance is taken as productivity (MacDuffie 1995; Huselid 1995; Guest and Hoque 1994; Ichniowski et al. 1997; Wood and de Menezes 1998; Patterson et al. 1997; Wright et al. 2003); this may be self-reported employee productivity (Youndt et al. 1996) or labour productivity: the ratio of sales to employees, e.g. input of labour per output of sales (Koch and McGrath 1996:343; Patterson et al. 1997; Cappelli and Neumark 2001; Guest et al. 2003); product quality (MacDuffie 1995; Guest and Hoque 1994; Youndt et al. 1996; Ichniowski et al. 1997; Wright et al. 2003); financial measures (Huselid 1995; Delery and Doty 1996; Wright et al. 2003; Patterson et al. 1997; Terpstra and Rozell 1993; Guest et al. 2003; Truss 2001; Wood and de Menezes 1998; Storey 2002); pay rates (Wright et al. 2003); turnover (Huselid 1995); labour efficiency (Arthur 1994); machine efficiency (Youndt et al. 1996); scrap rates (Arthur 1994); labour turnover (Arthur 1994; Wood and de Menezes 1998); job creation (Wood and de Menezes, 1998); absenteeism (Wood and de Menezes 1998); perceived organizational performance and perceived market performance (Delaney and Huselid 1996); Tobin's $q$ (natural log of the ratio of a firm's market value to the replacement cost of its tangible assets) and gross rate of return on assets (GRATE) (Huselid and Becker,

1996). Small wonder then that Becker and Gerhart argue for 'natural, meaningful metrics' (1996:791).

Against this wealth of financial measures, the human side of organisation is less well represented. Dyer and Reeves (1995:661) group performance measures as: human resource outcomes (absenteeism, turnover, individual/group performance); organisational outcomes (productivity, quality and service); financial/accounting (return on invested capital or on assets); and stock-market performance (stock value or shareholder return). Many studies have used organisational and financial outcomes, while very few have used HR outcomes (Wright et al., 2003). [10, pp. 5-7] 
Instead, I use emotional intelligence as an interface between individual performance, because its effectiveness in interpersonal communication, coordination ability, organization of individual and group work. [45] By contrast, I will try to confine me to develop the relationship between self-monitoring and performance (Snyder, 1983), which is closely related to the self-determination, because the studies are contradictory, and my research undertaken by size of self-monitoring have confirmed only those studies that demonstrate that there is connection between the two concepts, but that just may be a better predictor along with other factors in improving performance and is irrelevant in organizations (Day et all, 2002).[13, pp.85-89]

Regarding psychological factors which I will study the research are the 5 main factors. In relation to these factors, there are 2 major paradigms: the paradigm of "Big Five" and "Five Factor Model". Research factorial of personality psychology and related psycho-lexically converge on the same model causes of personality called "Five Factor Model" (factorial approach / paradigm factorial) or "Big Five" (lexical approach / paradigm hypothesis lexical) Big Five model and paradigm.

Researchers lexical paradigm, those who practice initiated studies in this area, follow the discovery by analyzing the structure of personality and common language have developed their own design called "Big Five. As we have seen, these authors argue that all the traits that determine individual differences will be represented in language and ordinary language analysis we could achieve a comprehensive taxonomy of personality attributes. [16, pp.5-29] On the other hand, concerns the discovery of structure of personality in terms of information provided by questionnaires led to a paradigm called "Five Factor Model". Distinctive for this paradigm is to use data collected through questionnaires and analyze the factors in reducing the use of diversity data. This methodology allowed them to validate the assumption that all traits of personality can be reduced to five independent factors, among which there are no significant correlations. I will follow Five Factor Model paradigm and operationalize the model factors Goldberg (1999), a model of personality with an overview of the 5 super factors, each factor having attached 6 facets[11, pp.218-220]

There are many meta-analysis demonstrating the validity of personality traits as predictors of performance. The Big-Five sums up the best predictors of performance in the area of personality traits, conscientiousness is the most effective of the 5 factors for predicting performance.

The relationship between conscientiousness and performance is the most stable since it was identified in all fields. Conscientiousness exerts its effect on performance through various mechanisms, such as perseverance and commitment to the goals [6, pp 186-208]. Barrick, Mount and Judge (1991) have identified 2 factors of the Big-Five model as being sufficiently strong correlations to be predictors of performance able-bodied. Their research indicates that conscientiousness factor explains $22 \%$ of performance variance, and extroversion explained 13\%. Hurtz and Donovan (2000) obtained similar results, conscientiousness having a coefficient of 0.22 . They are used in research as contextual performance evaluation and performance in specific tasks (Hurtz and Donovan cit. In Hogan and Holland, 2001). Tett, Jackson and Rothstein (1991, apud Hogan and Holland, 2001) have identified all Big-Five factors model to have predictive power for performance in extroversion $(0.16)$ to grateful (0.33). Dalton and Wilson (2000), in a research conducted on the 21 managers working in another country than their own, have identified a correlation of 0.47 between conscientiousness and overall performance. The explanation given by the researchers these results is that conscientiousness factor describes their responsibilities and pleasant, efficient management related behaviors. [2,pp. 11-18;4, pp. 250-258] 


\section{The Case Study}

Company - Rental car

Problem: finding and shaping factor that determines performance in the workplace because the objectives were not achieved in the last 6 months due to inefficiency and because of this staff are threatened jobs

Steps:

1.Collect information

- Identifying problems through the application of questionnaires regarding: requirements and job demands, the role of each in company, with who interact, problems faced and their opinion about the decision was announced (Joint survey between dimensions of organizational climate, the analysis of job, additional questions to capture the dimensions like and family size, internal facilities, the impact on the profile market, valuation of professional colleagues legally).

- Qualitative and quantitative analysis to identify the factors that hinders the achievement of performance: the intra-and inter-relationships, attitudes towards management, undefined clear of responsabilities related, even overlapping positions in the review responsibilities, vertical and horizontal communication, performance evaluation after surrealist criteria, families of origin (professional recognition, number of members), ineffective team work, the manifestation of counterproductive employee behavior, security and social protection offered by the employer, the job requirements, attachment to the company, age, environment of origin.

- Interviews with main individual and group interviews with members of each department and manufactory to confirm or invalidate factors identified, causes inefficiency and how they would like to solve the problems

- Communication official of identified positive and negative factors, methods of improvement and control

- Focus groups on professional development at work and solve problems identified and subsequently approved by company employees

- Psychological evaluation of employees to capture their strengths and weaknesses points and advising them to raise awareness of strengths and weaknesses

2. Identification and confirmation of the factors and problems that may affect work performance

- "Nomadic people" staff that had to be liaison between sales and service, was the fact that people who always passed from one camp to another, censored or incomplete information was provided very favorable to squabble when work had to be highest

- Links of communication problem: receptionist, technical advisor, chief of service, head of branch

The evaluation: fairness, persistence of decisions

- Reorganization of posts and job descriptions: clarity, the load

- The approach of staff depending on personality, $100 \%$ professional, but unique personality, even difficult

- How to address a problem that may face departments: nonexistent communication between teams in establishing a common goal

- The making and transmitting decisions by management: democratic, authoritarian, but not with authority substrate

- Lack of activity carried emotional side - high excellence without emotional involvement, emotional attachment towards the company only from first-mover

- Reorganization of predetermined motion time system work in technical department: reorganizing manufactorys, how to work on teams, elimination of some activities that required time receptionist, but ineffective for the service, the introduction of department of sales exceeding service to the customer did not show discrepancies.

3. Setting goals and actions for the next 2 months each, with a monthly assessment 
Example: car driver:

1 months - Primary objective: increasing the number of cars repaired with 2-4cars

- Secondary objectives: to establish and adapt activities according to the type of mechanical repair and availability of aid, improving the relationship with the customer after the reception, any new customer who has purchased a car is presented at technical team, any unsatisfied attitude is required by the customer in the box with the dots and the receptionist and mecanic to resolve problems amicably, people searching for functions and body shop manager and head damage, early activation of customers on special vehicles division, finding the marketing department a way adapted region to promote services service, the assessment of activity by management, improving the transmission of informations, etc

Evaluation at the end of month by interview and the employee's proposal or concerns about the solutions to problems and events with possible to confront 2 months-Primary objective: achieving the target of 6 months ago and to justify the annual wage negotiations

- Secondary objectives: increasing the number of cars entered in service with the number 2 and 2 special vehicles, engaging in the 2 position initially identified and their professional formation, firing an employee, cancellation green phone complaints, increase in labor payment for each car entered into service over accepted target level, achieving a team-building with employees and their family members, obtaining positive descriptions of the national dealer training to the regular assessment

Evaluation - checking compliance target of 9 months ago and exceeding it by $40 \%$. 4. Results: Increasing the salary after 3 months, increasing the payment from the machines in workmanship and in service, sales growth in division trucks, reorganization items and job descriptions, request after 6 months of the employees of a new assessment to identify potential disturbance due to hiring a significant number of employees

\section{Conclusions}

Identifying factors affecting performance at work from different categories and combining them may influence positively or negatively. A correct identification and reconfirmation of their factors through qualitative analysis, will allow employees to be given opportunities to develop credible and professional opportunities, but also for obtaining performance to assure workplace satisfaction.

Disorganization of informations on factors that can be identified from a job as a model, I was determined to achieve a more exploratory study to determine how literature can be found in a small company in Romania. It was clear that those factors which are the predominant mode of decision making, behavior and level of communication with colleagues, by way of transmission, but these differences are due to the different personalities that are involved in the performance. For different personalities different methods are needed to address them to achieve performance.

These factors that we have offered and purpose by setting improvement objectives and their performances, has led to awareness of the importance of such factors from management but also employees.

\section{Bibliography}

1. Bakker, A.B., Demeronti, E., Verbeke, W. (2004), Using the job demands-resources model to predict burnaout and performance, Human Resouces Management, Spring

2. Barrick R. M., Mount K. M. şi Judge A. T.(2001), Personality and performance at the begining of the new millennium: what do we know and where do we go next, International Journal of Selection and Assessment vol 9, issue 1\&2, pag 9-30 


\section{Studies and Scientific Researches - Economic Edition, no. 15, 2010}

3. Beh, L., Raduan, C.R, (2007), Linking QWL and job performance: implication for organization, Performance Imporvment, vol 46, nr 6, 30-35

4. Dalton, M., Wilson, M. (2000), The relationship of the five-factor model of personality to job performance for a group of middle eastern expatriate managers, Journal of Cross-Cultural Psychology, vol. 31 , nr. 2, p. $250-258$

5. Fisher, C.D. (2003), Why do lay people believe that satisfaction and performance are correlated? Possible source of commonsense theory, Journal of Organizational Behavior, vol 24, 753-777

6. Fong, E. A., Tosi, H.b L. Jr (2007), Effort, performance and conscientiousness: an agency theory perspective, Journal of Management, vol.33, nr. 161-179

7. Forero, C.G., Galardo-Pujol, D., A longitudinal model for predicting performance on police officers using personality and behavioral data, Criminal Justice and Behavior, 36, 591-606

8. Gagné, M., Deci, E.L. (2005), Self-determination theory and work motivation, Journal of Organizational Behavior, vol 26, 331-362

9. Grote, D., (2002), The performance appraisal question answer boock: survival guide for managers, AMACOM, SUA

10. Grugulis, I., Stoyanova, D., Skill and performance, Paper presented at the International Labour Process Conference, 21st - 23rd March 2005, University of Strathclyde

11. Mathews, G., Deary, I.J., Witeman, M.C. (2005), Psihologia personalitățiii, Ed. Polirom, Iaşi

12. Mohammed, S, Mathieu, J.E., Bartlett, A.L. (2002), Technical-administrative task performance, leadership task performance, and contextual performance: considering the influence of team-and taskrelated composition variables", Journal of Organizational Behavior, vol 23, 795-814

13. Moser, K., Galais, N., (2007), Self-monitoring and job performance, International Journal of Selection and Assessment, vol 15, nr 1, 83-93

14. Riketta, M.(2002), Attitudinal organizational commitment and job performance: a meta-analysis, Journal of Organizational Behavior, vol 23, 257-266

15. Rode, J. C., Mooney, C.H. (2007), Emotional intelligence and individual performance: evidence of direct and moderated effects, Journal of Organizational Behavior, vol 28, 399-421

16. Rolland, J. P., (2002), Cross-Cultural Generalizability of the Five Factor Model of Personality, in The Five Factor Model of personality Across Culture (coord. Robert R McCrae , Juri Allik), pag 5-29, Springer 